\title{
The effects of chemical kinetic mechanisms on large eddy simulation (LES) of a nonpremixed hydrogen jet flame
}

\author{
Xuejin Zhou ${ }^{\text {a }}$, Xi Jiang ${ }^{\text {* }}$, Daniel Mira ${ }^{c}$ \\ a Department of Safety Science Engineering \& State Key Laboratory of Fire Science, \\ University of Science and Technology of China, Hefei, Anhui 230026, China \\ ${ }^{\mathrm{b}}$ Engineering Department, Lancaster University, Lancaster LA1 4YR, United Kingdom \\ ${ }^{\mathrm{c}}$ Barcelona Supercomputing Center (BSC-CNS), Barcelona, Spain \\ *Corresponding author. Email: x.jiang@lancaster.ac.uk
}

\section{Highlights}

- A nonpremixed hydrogen flame was simulated using LES with detailed chemistry.

- Effects of five different kinetic mechanisms on the LES results were examined.

- The linear eddy model was employed for the turbulence-chemistry interactions.

- Detailed $\mathrm{H}_{2} / \mathrm{O}_{2}$ mechanisms lead to reasonable agreements with experimental results.

\begin{abstract}
Five different chemical mechanisms for hydrogen combustion are employed in large eddy simulation of a nonpremixed hydrogen jet flame to investigate the ability of these mechanisms to represent the turbulence-chemistry interactions and other combustion phenomena. The mechanisms studied include a reduced mechanism, two detailed $\mathrm{H}_{2} / \mathrm{O}_{2}$ reaction mechanisms, as well as a detailed $\mathrm{H}_{2} / \mathrm{CO}$ mechanism and the GRI3.0 mechanism. Linear eddy model is incorporated to evaluate the effect of turbulence-chemistry interactions. Extensive simulations of a well-known experimental case (German Aerospace Centre DLR nonpremixed flame M2) have been performed for the purpose of validation. Comparisons against experimental data
\end{abstract}


including scalar distribution profiles are presented where a reasonable agreement is observed for the detailed mechanisms. Flux analyses of the species conservation equations and ignition delay time tests showed that chemical kinetics plays a role in the development of flame structures in the jet flame. This study highlights the importance of precise descriptions of the chemical kinetics in LES of nonpremixed hydrogen combustion.

Keywords: detailed chemistry; hydrogen combustion; large eddy simulation; linear eddy model; nonpremixed flames

\section{Introduction}

Hydrogen utilization has gained great attentions because of the increasing interests in low-carbon economy in recent years. Hydrogen-enriched fuels are an attractive alternative for power generation since it can be produced from a variety of methods including both renewable and non-renewable resources [1]. However, the usage of hydrogen is accompanied by significant scientific and technological challenges. Hydrogen has some specific characteristics that make it very different from traditional fossil fuels. Property characteristics such as high diffusivity, wide flammability range, short ignition delay time, and high flame temperature not only make the use of hydrogen unsuitable for the traditional combustion systems, but also increase the potential of explosion hazards [2, 3]. Numerical modelling of hydrogen combustion also needs specific treatments [4]. One of the most complex problems in hydrogen combustion modelling is the calculation of turbulence-chemistry interactions which affect the temporal and spatial scales related to a wide range of vortices. To investigate the mechanisms controlling these interactions, experimental apparatus has been utilised over the past decades. The nonpremixed flame experiments performed in the cooperative framework of the International Workshop on Measurements and Computation of Turbulent Nonpremixed Flames (TNF) are well-known benchmark cases that have been numerically simulated by many authors, e.g. [5-10]. Among these, the burner in DLR Stuttgart [11] was designed with the aim of 
creating strong turbulence-chemistry interactions in a stable nonpremixed flame with relatively simple fluid mechanics and turbulence structures, which have been widely used in the validation of hydrogen combustion simulations.

Nonpremixed flames are very sensitive to flame-turbulence interactions and therefore, when performing modelling studies, the selected chemistry model has to be able to capture these effects. Besides, hydrogen is an important intermediate species in the oxidation of hydrocarbons as well as of oxygenated fuels. The elementary kinetics of $\mathrm{H}, \mathrm{O}, \mathrm{OH}, \mathrm{HO}_{2}$ and $\mathrm{H}_{2} \mathrm{O}_{2}$ determine the composition of the radical pool in other fuel reaction systems. In general, a detailed chemical mechanism is needed for accurate modelling of the flames, which can be useful for in-depth understandings of hydrogen combustion kinetics as well as hydrocarbons. Numerous kinetic mechanisms about hydrogen/hydrocarbon have been proposed and validated through various experimental data in the literature, e.g. [12-18]. However, three-dimensional calculations with detailed chemistry are usually prohibitively expensive when one tries to resolve all the relevant scales. Accordingly, there have been studies using simplified approaches to the combustion kinetics such as the flamelet generated manifold reduction, e.g. $[19,20]$.

A noticeable and expensive study using three-dimensional direct numerical simulation (DNS) with detailed chemistry was performed for the investigation of flame stabilization in a lifted hydrogen jet flame [21]. Analysis of the relative locations of key intermediate species and reaction flux show the presence of autoignition as a stabilization mechanism occurring near the flame base. Other studies with different detailed kinetic mechanisms were carried out for hydrogen-air mixtures using the LES approach [22, 23], the joint scalar PDF method [7], and the conditional moment closure model [24]. However, comparisons of the mechanisms were generally restricted to simple zero- or one-dimensional laminar computations, like ignition in a fully premixed mode, freely propagating laminar premixed flames or counter-flow flames. Numerical simulations of the TNF cases or other flames with evaluation of detailed mechanisms have been performed in two-dimensional domains $[7,25,26]$. Since turbulence is intrinsically a three-dimensional phenomenon and turbulent flames in three-dimensional 
computations are necessary for understanding combustion in practical systems, it is important to perform a study on the influence or performance of different chemical kinetics on modelling the turbulence-chemistry interactions for nonpremixed turbulent flames in a three-dimensional domain.

Prediction of turbulent flames also requires proper turbulent mixing models to represent the flow field structures. It is generally accepted that large eddy simulation approaches exhibit improved predictions for unsteady mixing processes compared to the traditionally used Reynolds-averaged Navier-Stokes modelling methods [27]. The LES approach is based on resolving the large scales of the flow and modelling the small scales. It is used to study the complex unsteady turbulent reacting flows in this work. LES of reacting flows has been extensively applied to study both nonpremixed and premixed jet flames, including ignition/extinction processes $[28,29]$. Ignition events in LES take place at small scales and therefore subgrid scale models are required. In this context, the linear eddy model (LEM) [30, $31]$ is employed to represent the turbulence-chemistry interactions.

The present study aims at testing and validating several kinetic mechanisms to model the combustion of hydrogen-enriched fuels. This work provides a practical way to investigate the mechanisms concerning the identification of chemical pathways, the evaluation of performances, and the validation of chemistry reduction techniques. A brief description of the test case for validation is given in the next section, followed by concise descriptions of the chemical mechanisms, the main aspects of the LES-LEM approach and the numerical setup. Results are reported and compared with experimental data subsequently. Then analyses on ignition delay times are carried out and some conclusions are drawn at the end.

\section{Test case description}

The flame considered in this work is one of the series of nonpremixed $\mathrm{H}_{2} / \mathrm{N}_{2} /$ air jet flames in the database of TNF Data Archives-DLR [11]. The denoted flame M2 is the combustion of hydrogen diluted in nitrogen with a composition of $75 \% \mathrm{H}_{2}+25 \% \mathrm{~N}_{2}$ in mole fraction. 
Detailed descriptions of the experiments and the characteristics of flame M2 can be found in the literature [11]. The nozzle diameter of the burner is $D=0.8 \mathrm{~cm}$, and the inlet velocity is $u_{\text {jet }}$ $=4230 \mathrm{~cm} / \mathrm{s}$, based on which the Reynolds number is calculated as $R e=9300$. The fuel ejected to the tube nozzle inlet is diluted in $\mathrm{N}_{2}$ to reduce the heat losses by radiation. The flame is stabilized by a coflow air at $30 \mathrm{~cm} / \mathrm{s}$. The ignition procedures can be established by either a spark or a pilot. This case was selected because the flame is characterised by preferential diffusion at the upstream locations and the turbulence-chemistry interactions are obviously stronger than those in a laminar flame.

The computational solution domain is a three-dimensional cylinder, of an extent $(0,25 D)$ in the axial $(z)$ direction, and $(0,11 D)$ in the radial $(r)$ direction. An extrusion of $0.3 \mathrm{~cm}$ is included in the bottom which accounts for the fuel injection tube. A schematic representation of the computational domain is shown in Fig. 1.

At the inlet plane, a top hat velocity profile is defined. The coflow boundary is treated as a non-slip wall. The fuel is a mixture of hydrogen and nitrogen, while the coflow is air. The fuel jet and coflow temperatures at the inlet are set to be $1100 \mathrm{~K}$ and $298 \mathrm{~K}$, respectively. The hot fuel ejected into the air leads to autoignition. A Dirichlet-type boundary condition for the pressure is used at the azimuthal boundary. In the exit plane, non-reflecting continuative boundary conditions are imposed to avoid reflection of acoustic waves back into the domain.

\section{Model description}

The physicochemical models and the numerical procedures used in the simulations are described in this section, including three sub-sections dealing with the chemical mechanisms, the LES-LEM approach and the numerical procedures.

\subsection{Reaction mechanisms for hydrogen combustion}

A large number of detailed, reduced or global mechanisms including $\mathrm{H}_{2} / \mathrm{O}_{2}$ kinetics can be found in the literature. Most of the detailed ones are dedicated to the combustion of 
hydrocarbons with sub-mechanisms for $\mathrm{H}_{2} / \mathrm{O}_{2}$ kinetics, but an accurate description of the $\mathrm{H}_{2} / \mathrm{O}_{2}$ subset is also essential for the overall performance of hydrocarbon mechanisms. In this study, five most recent mechanisms are selected, which have been widely used and/or validated for hydrogen combustion.

The well-known Gas Research Institute (GRI) mechanism has been developed for $C_{1} / C_{2}$ kinetics [16]. It is an extensively used standard kinetic mechanism for modelling the combustion of hydrocarbons. Although it is optimised for nature gas, validations against experimental data have also been performed for hydrogen combustion [33, 34]. The most recent version "GRI-Mech 3.0" including 28 reversible reactions for $\mathrm{H}_{2} /$ Air kinetics is used in this study.

Based on the GRI3.0 (represents "GRI-Mech 3.0" hereinafter), some recently improved mechanisms for hydrogen combustion can be found. A comprehensive $\mathrm{H}_{2}-\mathrm{CO}$ mechanism by Davis et al. [12] used the 20 reactions contained in GRI3.0 for $\mathrm{H}_{2} / \mathrm{O}_{2}$ chemistry, listed in Table 1, with a few rate coefficients updated. Furthermore, Hong et al. [13] presented a mechanism based on the same 20 reactions in a form identical to that found in GRI3.0; however most of the reaction rate constants from the GRI3.0 mechanism are not retained.

Another well-established scheme for hydrogen combustion is a 19-step detailed mechanism in which (R14) $\mathrm{H}+\mathrm{HO}_{2}=\mathrm{H}_{2} \mathrm{O}+\mathrm{O}$ was not included [17]. Mechanisms premised on it have been developed for years. One of recent mechanisms by Ó Conaire et al. [14] shows good agreement when validated against experiments at temperatures ranging from 298 to $2700 \mathrm{~K}$, pressures from 0.05 to $87 \mathrm{~atm}$, and equivalence ratios from 0.2 to 6 . It is also employed in the calculations performed.

In addition to the detailed mechanisms, a most recent reduced mechanism by Boivin et al. [15] which represents a 3-step or 12-step reduced finite-rate chemical kinetic mechanism based on the fuel mixture is considered in this study. It is a reduction from the well-known San Diego kinetic mechanism [18] by an assumption of $\mathrm{OH}, \mathrm{O}$ and $\mathrm{H}_{2} \mathrm{O}_{2}$ being in steady-state. It was designed to deal with high-temperature autoignition and flame propagation. Specifically, a 
correction was included in the mechanism based on an eigenvalue analysis of the chain reactions (R1-R4) between reactants and the main radicals, to improve autoignition. This mechanism has been successfully applied to flame M2 [35].

The five chemical mechanisms considered in this work - GRI3.0 [16], Davis et al. [12], Hong et al. [13], Ó Conaire et al. [14] and Boivin et al. [15], are listed in Table 2. According to the literature, all of these mechanisms have been validated in some kinds of premixed/nonpremixed laminar flames, as well as autoignition tests, for a wide range of pressure, temperature and equivalence ratio.

\subsection{Mathematical model}

By resolving all relevant length scales, the LEM accounts for the effect of turbulent mixing effectively. It has the ability to demonstrate the small scale processes taking place in the flow which are of great importance to precisely describe turbulent mixing and combustion [30]. One of the main advantages of the LEM is its ability to directly incorporate the chemical reaction term without any modelling assumption since all subgrid scales are resolved by the LEM solver. The physical process including subgrid turbulence convection, molecular diffusion and chemical reaction are modelled in a one-dimensional domain immersed in each LES cell according to the conventional LEM approach proposed by Kerstein [31, 32]. LEM works on all temporal and spatial scales. Due to its simplicity, LEM allows for parametric studies such as varying the turbulence intensity, and performing large scale simulations under affordable computational costs.

Similar to other conventional LES methods, the LES-LEM approach calculates the large scales explicitly by the filtered transport equations, while the unsolved small scales are dealt with using subgrid models. The spatially Favre filtered governing equations are the mass conservation equation, the momentum transport equations, the energy conservation equation and the subgrid kinetic energy equation, which is used to close the subgrid stress in the momentum equation through an eddy viscosity model. One can find this set of equations as follows or elsewhere [4, 27]. 


$$
\begin{gathered}
\frac{\partial \bar{\rho}}{\partial t}+\frac{\partial \bar{\rho} \tilde{u}_{j}}{\partial x_{j}}=0 \\
\frac{\partial \bar{\rho} \tilde{u}_{i}}{\partial t}+\frac{\partial \bar{\rho} \tilde{u}_{i} \tilde{u}_{j}}{\partial x_{j}}=-\frac{\partial \bar{p}}{\partial x_{i}}+\frac{\partial}{\partial x_{j}}\left(\overline{\rho \nu} \tilde{S}_{i j}\right)-\frac{\partial \tau_{i j}^{s g s}}{\partial x_{j}} \\
\frac{\partial \bar{\rho} \tilde{e}}{\partial t}+\frac{\partial \bar{\rho} \tilde{u}_{j} \tilde{e}}{\partial x_{j}}=-\bar{p} \frac{\partial \tilde{u}_{j}}{\partial x_{j}}-\frac{\partial \bar{q}_{j}}{\partial x_{j}}+\bar{\tau}_{i j} \frac{\partial \tilde{u}_{i}}{\partial x_{j}}-\frac{\partial h_{j}^{s g s}}{\partial x_{j}}+\Theta^{s g s}+\bar{Q}^{c} \\
\frac{\partial \bar{\rho} k^{s g s}}{\partial t}+\frac{\partial \bar{\rho} \tilde{u}_{j} k^{s g s}}{\partial x_{j}}=-\tau_{i j}^{s g s} \frac{\partial \tilde{u}_{i}}{\partial x_{j}}-C_{\varepsilon} \frac{\bar{\rho}}{\Delta}\left(k^{s g s}\right)^{3 / 2}+\frac{\partial \bar{\rho} \tilde{u}_{j} k^{s g s}}{\partial x_{j}}\left(\frac{\bar{\rho} v_{t}}{P r_{t}} \frac{\partial k^{s g s}}{\partial x_{i}}\right)
\end{gathered}
$$

In above equations, $x_{1}=X, x_{2}=Y$ and $x_{3}=Z$ are used; subscript $s g s$ represents subgrid scale variables; $\tilde{u}_{i}$ is the Favre filtered $i$ th velocity component. $\bar{\rho}, \bar{p}, \tilde{e}$ are the density, pressure, and internal energy respectively, while $k^{s g s}, \bar{q}_{j}, h_{j}^{s g s}, \Theta^{s g s}$ and $\overline{\dot{Q}}^{c}$ are the subgrid turbulent kinetic energy, heat flux, subgrid scale enthalpy flux, subgrid scale viscous work and heat release respectively. In Eq. (4), $v_{t}=C_{v} \sqrt{k^{s g s}} \Delta$ is the subgrid eddy turbulent viscosity; $S_{i j}$ and $\tau_{i j}$ are the strain rate tensor and filtered stress tensor respectively. $\operatorname{Pr}_{t}$ is the subgrid Prandtl number, and $C_{\varepsilon}, C_{v}$ are constants.

The velocity field is split into a filtered LES-resolved part $\tilde{u}_{j}$ and a fluctuation component which can be in turn decomposed into an LES-resolved fluctuation $u_{j}^{\prime}$ and an unresolved subgrid fluctuation $u_{j}^{\prime \prime}$. This general decomposition of the instantaneous velocity field can be written as $u_{j}=\tilde{u}_{j}+u_{j}^{\prime}+u_{j}^{\prime \prime}$. With which the species conservation equation can be written as:

$$
\frac{\partial\left(\rho Y_{m}\right)}{\partial t}+\frac{\partial}{\partial x_{j}}\left[\rho\left(\tilde{u}_{j}+u_{j}^{\prime}+u_{j}^{\prime \prime}\right) Y_{m}\right]=\frac{\partial}{\partial x_{j}}\left(\rho D_{m} \frac{\partial Y_{m}}{\partial x_{j}}\right)+\dot{\rho}_{m}^{c}
$$

where $Y_{m}$ is the mass fraction of the species $m, \dot{\rho}_{m}^{c}$ represents the source terms. Eqs (4) - (5) are solved by an explicit scale separation approach. The subgrid scale processes considered in this study are the molecular diffusion and the turbulent stirring, since chemical reactions are not resolved in the one-dimensional LEM domain in this work. The process of large-scale 
advection is implemented separately in the resolved field with contributions from the subgrid scale. Eq. (5) is split into two sub-steps in the implementation:

$$
\begin{gathered}
Y_{m}^{n+1 / 2}-Y_{m}^{n}=\int_{t}^{t+\Delta t L E S}\left[-u_{j}^{\prime \prime} \frac{\partial Y_{m}}{\partial x_{j}}+\frac{1}{\rho} \frac{\partial}{\partial x_{j}}\left(\rho D_{m} \frac{\partial Y_{m}}{\partial x_{j}}\right)\right] \mathrm{d} t \\
Y_{m}^{n+1}-Y_{m}^{n+1 / 2}=\int_{t}^{t+\Delta t L E S}\left[-\left(\tilde{u}_{j}+u_{j}^{\prime}\right) \frac{\partial Y_{m}}{\partial x_{j}}\right] \mathrm{d} t
\end{gathered}
$$

where $\triangle t L E S$ is the timestep from $\mathrm{n}$ to $\mathrm{n}+1, Y^{n+1 / 2}$ is the mass fraction in the intermediate stage. Eq. (6) represents the subgrid scale process. In LEM, this scalar transport is computed by solving a one-dimensional reaction-diffusion equation with a turbulent advection model. Accordingly, it leads to the following expression:

$$
\frac{\partial Y_{m}}{\partial t}=\frac{1}{\rho} \frac{\partial}{\partial s}\left(\rho D_{m} \frac{\partial Y_{m}}{\partial s}\right)+F_{s t i r}
$$

where $s$ represents the coordinate along the LEM domain, and $F_{s t i r}$ is the advection by small scale fluctuations (stirring) modelled by the triplet map [31]. Eq. (8) is time integrated using a time step $\Delta t_{\text {diff }}$ imposed by the local subgrid diffusion (or chemistry) scales and determined by:

$$
\Delta t_{d i f f}=C_{\text {diff }} \frac{\Delta s^{2}}{\max \left\{v, D_{m}\right\}}
$$

where $C_{\text {diff }}$ is a constant taken as 1.0 for numerical stability purpose, $\Delta$ is the size of the LEM cell. The effect of the subgrid convection is represented by $F_{\text {stirr }}$ which is modelled as in the original LEM model by the stochastic triplet map. These events are characterised by two parameters: a mapping frequency and a probability density function of subgrid turbulent eddy size $l$, given by [36]:

$$
\begin{gathered}
f(l)=\frac{5}{3} \frac{l^{-8 / 3}}{\eta^{-5 / 3}-\Delta^{-5 / 3}}, \eta<l<\Delta \\
\lambda=\frac{54}{5} \frac{v R e^{s g s}}{C_{\lambda} \Delta^{3}} \frac{(\Delta / \eta)^{5 / 3}-1}{1-(\Delta / \eta)^{4 / 3}}
\end{gathered}
$$


where $\eta$ represents the Kolmogorov length scale, $C_{\lambda}$ is a model constant. In the above equations, $R e^{s g s}=u^{\prime} \Delta / v$ is the subgrid Reynolds number. From the frequency $\lambda \Delta$, the time step among triplet-map events can be determined as:

$$
\Delta t_{\text {stir }}=\frac{1}{\lambda \Delta}
$$

The convective transport caused by the resolved field and the turbulent fluctuations is accounted for by the implementation of a Lagrangian volume-of-fluid method using the splicing technique proposed by Kerstein [31, 32]. Considering that the small scale turbulent fluctuations are isotropic, the unresolved scale flux is estimated from the subgrid scale turbulent kinetic energy, while the resolved scale flux is computed directly from the LES equations.

\subsection{Numerical algorithms}

The LES-LEM approach is implemented in a parallel unstructured finite-volume code $[4,37]$ that solves the above time-dependent governing equations. Careful attentions are needed for defining the timestep of the simulation in the computations. The spatial differencing is computed in two steps. Step 1 corresponds to the computation of the diffusive terms present in the momentum, energy and mass conservation equations, to obtain the pressure field by the conjugate residual method through a modified SIMPLE algorithm. The one-dimensional subgrid scale diffusion equation is computed and coupled to the filtered equations. The convective transport of the scalar variables and momentum fluxes are computed in Step 2 using a quasi-second order upwind differencing approach. Here in the reaction sub-step of the LEM calculations, the mixture in each cell reacts and proceeds to the next step through an adiabatic constant-pressure process. The cell thermo-chemical composition is taken to be temperature, species mass fractions and density. The chemical time scale should be smaller than the time scale in turbulence. In this work, time step in chemical reaction calculation was set as one fifth of the turbulent time step and no more than $0.5 \mu \mathrm{s}$. The reaction equation is integrated using the DVODE solver $[38,39]$. In a CFD calculation that uses detailed chemistry, the computational 
time spent in the reaction computation is in general dominant. Numerical integration is used in marching the solution in time, with the diffusion computed implicitly.

Several tests were performed for flame M2 using the five mechanisms in this study. These tests were performed on grids of 0.8 million and 1.2 million, respectively; and with time averaging over at least 30000 steps (more than $60 \mathrm{~ms}$ ) after the ignition. The comparisons of these tests with different meshes show that the numerical errors of both time averaged velocities and temperatures are generally no more than $2 \%$ (with respect to the radial profile in three axial locations). The results reported in this work were computed on the grid of 0.8 million. The mean and root mean square (RMS) results presented in this article represent data obtained from the plane of $x=0$.

\section{Results and discussion}

\subsection{Instantaneous results}

Fig. 2 illustrates the three-dimensional instantaneous iso-surfaces of temperature and vorticity magnitude; the instantaneous results represent $24 \mathrm{~ms}$ after the beginning when the flame reached the outlet boundary. The cross-stream vorticity component $\omega_{1}$ for the five computational cases at a given time instant is defined as:

$$
\omega_{1}=\frac{\partial u_{2}}{\partial x_{3}}-\frac{\partial u_{3}}{\partial x_{2}}
$$

The flames are observed to be different in high temperature regions, in terms of three-dimensional shapes and vortical structures at this time instant. The case using the reduced mechanism by Boivin et al. [15] is more laminar-like since the flame shape seems to be smoother than that produced by the detailed mechanisms. Similar phenomena can be observed in the top of Fig. 3 which presents the instantaneous cross-sectional temperature contour plots at the same time instant. Focusing on the vorticity magnitude in Fig. 2, the selected iso-surfaces mainly exist in the shear layer and the head regions because of the large velocity gradients in these regions. Complex vortices transport heat and fuel mass by convection and this transport 
phenomenon leads to inhomogeneity and promotes large density and pressure gradients that continue vorticity generation. However, the vorticity distribution range in the cases of four detailed mechanisms is broader than that predicted by the reduced mechanism. Considering together with the flame shape, it can be qualitatively thought that the flame structures are affected by the kinetic mechanisms considerably.

Comparing the mean flame temperature profiles at the same cross-section in Fig. 3 , it is obvious that the reduced scheme produced the highest temperature in comparison with the other four detailed mechanisms. Another noticeable feature in instantaneous temperature profiles is that the flame heights are not the same. This is mainly because of the different ignition times which will be discussed subsequently.

\subsection{Comparison with experiments}

A quantitative comparison of the flames obtained in the five simulations is presented in Fig. 4(a)-(c). It represents profiles for mean values and RMS fluctuations of the temperature, mass fractions of the main species $\mathrm{H}_{2}, \mathrm{O}_{2}, \mathrm{H}_{2} \mathrm{O}$ at axial locations of $z / D=5, z / D=10$ and $z / D=20$ versus $r / D$, as obtained with mechanisms of GRI3.0 [16], Davis et al. [12], Hong et al. [13], Ó Conaire et al. [14] and Boivin et al. [15]. The simulated results are presented in five line plots while measurements are shown by circular symbols. Generally, qualitative agreements between the predictions and experimental data are observed for all chemical mechanisms employed. Most trends in both mean and RMS profiles are well captured by the LES-LEM approach with the chemical kinetics considered. This indicates that the LES-LEM method and all the mechanisms have the ability to describe the flame M2.

For the mean values, all the simulations capture the trends well, except the mean temperature profiles in the vicinity of the symmetry axis $(r / D<1)$, as shown in Fig. 4(a)-(c). The inlet fuel temperature in the simulation was $1100 \mathrm{~K}$ which led to auto-ignition taking place, while it was spark ignition under ambient temperature of $298 \mathrm{~K}$ in the experiments. The difference between the spark ignition and numerical initial conditions may contribute to the large deviations (about $500 \mathrm{~K}$ ) between the predictions and the experiments near the centreline, while this kind of 
disagreement does not appear in the species predictions. Except that, the agreement between the mean values and experiments is reasonable. The maximum temperatures predicted by the four detailed mechanisms are very close if the small difference in averaging period for the statistical analysis is taken into consideration. Meanwhile the reduced mechanism overestimates the maximum temperature by $200-300 \mathrm{~K}$ compared to the experiments. This is an inevitable drawback of using explicitly reduced chemical mechanisms [15]. Because the reduction techniques were performed with fewer intermediate species and/or steady-state assumptions for certain species in comparison with detailed schemes, the reduced mechanism could lead to over prediction of combustion heat release. In Fig. 4, it can be noticed that the positions of temperature peaks are generally well represented by the simulation results, especially at downstream locations.

RMS fluctuations in the simulations are comparable to the experimental measurements in terms of the overall tendency, but large differences are observed in the magnitudes and the peak values are not well reproduced. Specifically, the results generally under predicted the upstream peak values. However, the magnitudes and peak values were well captured in the downstream plane $z / D=20$. This is reasonable because the upstream flame evolves with a well-defined shear layer largely affected by the inlet conditions, but the flame becomes turbulent and wrinkled as it progresses downstream which is less dependent on the inlet conditions. The experimental perturbations at the nozzle inlet are complex with uncertainties, which cannot be reproduced by the artificial oscillations in velocity profiles employed in the simulations.

On the basis of species mass fraction, the profiles of mixture fraction in the same plane are shown in Fig. 5. The mixture fraction $\xi$ in this study is defined as:

$$
\xi=\frac{\left(1 / 2 M_{\mathrm{H}}\right)\left(Y_{\mathrm{H}}-Y_{\mathrm{H}, 2}\right)-\left(1 / M_{\mathrm{O}}\right)\left(Y_{\mathrm{O}}-Y_{\mathrm{O}, 2}\right)}{\left(1 / 2 M_{\mathrm{H}}\right)\left(Y_{\mathrm{H}, 1}-Y_{\mathrm{H}, 2}\right)-\left(1 / M_{\mathrm{O}}\right)\left(Y_{\mathrm{O}, 1}-Y_{\mathrm{O}, 2}\right)}
$$

where $Y_{\mathrm{K}}$ and $M_{\mathrm{K}}$ are the total mass fraction of element $\mathrm{K}(\mathrm{H}$ or $\mathrm{O})$ and molecular weight of element $\mathrm{K} ; Y_{\mathrm{K}, 1}$ and $Y_{\mathrm{K}, 2}$ are the element mass fractions in the unburnt fuel and in the coflow air, respectively. The stoichiometric mixture fraction is determined as $\xi_{\text {st }}=0.14$. The correct 
prediction of mixture fraction is essential to the calculation of nonpremixed turbulent combustion [7]. Radial profiles of mean mixture fraction derived from the five mechanisms are shown in Fig. 5. The agreements between all the calculations and the experimental data are generally acceptable. There are small but discernible differences between the calculations. Particularly, the prediction given by Boivin et al. mechanism [15] is slightly higher than the other four detailed mechanisms in the outer flame regime. It predicts most accurately downstream in the plane $z / D=20$ when $r / D>1.5$, while all the four detailed mechanisms under predict the mixture fraction.

As mentioned above, both the mechanisms by Davis et al. [12] and Hong et al. [13] use the same kinetics as GRI3.0 [16], but the predictions by Davis et al. [12] and GRI3.0 [16] are closer for many variables, even in the RMS fluctuations, especially in the plane $z / D=5$ which represents the flame base. However, it is not conclusive to say which scheme is more accurate or consistent than the others from the profiles since the four detailed chemical kinetic mechanisms present similar and well-enough predictions. To further evaluate the numerical results against experiments, scatter plots of temperature and species mole fractions are presented in Figs. 6-7. Only the Davis et al. [12], Ó Conaire et al. [14] and Boivin et al. [15] mechanisms are selected as typical cases for simplicity considerations.

In Fig. 6(a)-(b), the four rows of figures correspond to instantaneous experimental data, as well as numerical results by Davis et al. [12], Ó Conaire et al. [14] and Boivin et al. [15]. The data include temperature and three main species which cover nearly 1200 samples or a time evolution of about $50 \mathrm{~ms}$. In Fig 6(a), the scalar plots correspond to probing at the point $[r / D$, $z / D]=[1.0,5.0]$ which is close to the flame base in fuel-rich zones. The experiments show that temperature is distributed along the adiabatic equilibrium condition (solid line) and concentrated around a mixture fraction $\xi=0.2$, indicating that is the most reactive area. The range of fluctuating temperature values is not well illustrated for the same reason of inlet fuel conditions, but all the distributions of species are in good agreement. When focusing on the mixture fraction, it can be seen that Ó Conaire et al. [14] exhibits the best agreement in which the value range is precisely reproduced. For the next scatter plots in Fig. 6(b), results are shown 
for another probing point located downstream at $[r / D, z / D]=[3.125,20.0]$ which is turbulent in fuel-lean zones far from the nozzle inlet. Therefore, the influence of the inlet condition is negligible due to dissipation. As expected, the temperature and species are more similar to the experiment than those at the first probing point. Although the reduced kinetics of Boivin et al. [15] matches the mixture fraction fluctuation range well, the scatters tend to concentrate in the mixture $\xi \approx 0.02-0.08$ rather than in the lean mixture from zero as that in the experiments. The scattering of the points in the vertical direction of these plots is much thinner than that of the experiments, as shown in Fig. 6. It can be mainly attributed to the weaker RMS fluctuations in temperature and species profiles.

This study further compares the key intermediate species $\mathrm{HO}_{2}, \mathrm{H}$ and $\mathrm{OH}$ between the three detailed mechanisms, which were not measured in the experiments. Scalar plots of instantaneous species mass fraction versus mixture fraction are shown in Fig. 7, as obtained by chemistry of Davis et al. [12], Ó Conaire et al. [14] and Boivin et al. [15]. The data include all the points in the planes $z / D=5$ (blue scatters) and 20 (red) but eliminate non-reacting points (T $<500 \mathrm{~K}$ ) for better visual effects. Radical $\mathrm{OH}$ in the reduced Boivin et al. scheme [15] was not computed directly; instead it was estimated using the steady-state expression [15].

The recombination reactions involving the radical $\mathrm{OH}$ with either $\mathrm{H}_{2}$ or radical $\mathrm{HO}_{2}(\mathrm{R} 3, \mathrm{R} 6$, R14) constitute the main chemical pathway for $\mathrm{H}_{2} \mathrm{O}$ formation in hydrogen combustion. Therefore, as $\mathrm{OH}$ is formed at temperature peaks [35], it is in these regions where most of the $\mathrm{H}_{2} \mathrm{O}$ is formed. This process is well characterised by all the mechanisms and is confirmed through the different structure of $\mathrm{OH}$ concentration in Fig. 7 combined with temperature and $\mathrm{H}_{2} \mathrm{O}$ profiles in Fig. 3.

However, there are significant differences in the prediction of hydroperoxyl radical $\mathrm{HO}_{2}$ by the three mechanisms. First, the reduced chemistry significantly under predicts $\mathrm{HO}_{2}$ mass fraction. The second difference is that the $\mathrm{HO}_{2}$ peaks correspond to the mixture fraction near $\xi_{\text {st }}$ by the Boivin et al. mechanism [15] while the calculations by detailed kinetics are in lean mixtures. Previous studies $[10,19]$ also proved that the chemical production for $\mathrm{HO}_{2}$ radical occurs in a 
relatively narrow zone in the very lean mixture fraction. Even employed a 12-step reaction scheme, the reduced chemistry still cannot predict $\mathrm{HO}_{2}$ as precise as detailed kinetic schemes do. Another difference would be the cone zone shapes of $\mathrm{HO}_{2}$ scatters. As can be seen, the shape by Ó Conaire et al. [14] has a small shift to the right with the mixture fraction as the flame propagates downstream. In contrast, the predictions of $\mathrm{H}$ radical did not show so many dissimilarities by the three kinetic schemes.

Reactions R1 and R9 are of vital importance as they play a key role in controlling the chemical pathways in the ignition zone, and $\mathrm{HO}_{2}$ typically peaks in ignition zones. $\mathrm{HO}_{2}$ is mainly produced by reaction $\mathrm{R} 9$ from consumption of $\mathrm{H}$ radical and oxygen. So that upstream $\mathrm{HO}_{2}$ sinks in very lean mixtures. With radical $\mathrm{H}$ accumulating upstream, radical $\mathrm{HO}_{2}$ starts being consumed with $\mathrm{H}$ through reaction $\mathrm{R} 10$ further downstream. Therefore, $\mathrm{HO}_{2}$ concentrates in a richer mixture fraction. The mechanism of Ó Conaire et al. [14] gives a better representation of this process, as confirmed by comparison of $\mathrm{HO}_{2}$ distributions in the two planes.

In addition to the scatter plots, flux analyses of the contributions of chemical reactions in species conservation equations Eq. (5) are performed for radicals $\mathrm{H}$ and $\mathrm{HO}_{2}$, as shown in Fig. 8. The intensity of source terms is plotted versus radial distance. The different turbulence-chemistry interactions of radicals $\mathrm{H}$ and $\mathrm{HO}_{2}$ upstream and downstream are demonstrated again.

\subsection{Discussion}

Comparison of the shapes of the mean and RMS profiles in the flame, shown in Fig. 4, indicates that the mixing layer between hot fuel and the coflow is not well reproduced in the simulations. The simulated flames are generally wider than the experimental flame. This may be due to differences in the sampling methods used to obtain the RMS values in the simulations and experiments, in addition to the different inlet boundary conditions. Taking into account these differences, the flame simulations mostly capture the correct trends, indicating the impacts of the chemical kinetics on turbulence-chemistry interactions, which is the main objective of the present work. 
The detailed and reduced chemical schemes predict the mean values and RMS fluctuations very similarly for the main species. However, the maximum temperatures are generally over estimated about 200-300 K by the reduced scheme, as shown in Figs. 3-4. The key intermediate species analyses shown in Figs. 6-8 confirm that the detailed mechanisms are generally more accurate in describing the turbulence-chemistry interactions as the flame evolves, whereas the reduced mechanism is insufficient for predicting some radicals.

\section{Analysis of the ignition delay time}

This work was mainly aimed at performing a comparative study of different chemical kinetic mechanisms in a three-dimensional domain with LES approach. To further assess the five chemical kinetic schemes, the standard ignition delay time (IDT) has been analysed which largely decouples the effects of mixing and turbulence from chemistry. For the IDT analysis, simple calculations using the homogeneous model at constant pressure (1 atm) and enthalpy were carried out. The results were validated with shock tube experiments for stoichiometric hydrogen/air mixtures performed by Snyder et al. [40], Slack [41], Craig et al. [42], as shown in Fig. 9. Only part of the experimental data was selected [33]. The tests were accomplished using an in-house code modified from the well-known SENKIN code [43].

The definition of the IDT is of great importance, which can lead to different results. In previous studies, the IDT has been defined for DNS using the heat release rate [9]. One possibility is to define IDT as the time at which the marker variable, such as the temperature as well as radical $\mathrm{H}$ or $\mathrm{OH}$, reaches the maximum temporal gradient. However, these definitions become problematic for turbulent LEM simulations and sometimes they may incorrectly predict autoignition. LEM is a stochastic model that can generate large gradients when a stirring event occurs, making it difficult to use gradient as a criterion for defining ignition [38]. In this work, the ignition delay time was taken as the instant when both the maximum temperature increased by $800 \mathrm{~K}$ compared to the inlet fuel condition and the maximum mass fraction of radical $\mathrm{OH}$ reached $10^{-3}$ during a series of 100 computation steps. In fact, the tests indicated that the two 
criteria can almost be reached at the same time. The upper limit of IDT in the tests is set to be $100 \mathrm{~ms}$.

In Fig. 9, computed ignition delay times as a function of the inverse of temperature for the various reaction mechanisms are compared with these measurements. The IDTs given by the five mechanisms are very close when the temperature is relative high (over 1100K). In the lower temperature regions, the mechanisms of GRI3.0 [16] and Hong et al. [13] considerably over predict the ignition delay time. In the meantime, mechanisms of Davis et al.[12] and Ó Conaire et al.[14] agree well for temperatures around 900-1000K, and the Ó Conaire et al. yields slightly better agreement. The predictions from the reduced mechanism fall in-between the two sets of kinetics.

Autoignition tests have also been performed for the flame M2 $\left(75 \% \mathrm{H}_{2}+25 \% \mathrm{~N}_{2}\right)$ with all the five mechanisms. The ignition delay times obtained are shown in Fig. 10. The IDTs from the mechanisms of Hong et al. [13] and Ó Conaire et al. [14] are almost identical to GRI3.0 [16]. All of them could not ignite within $100 \mathrm{~ms}$ when the initial temperature was decreased to 1045 K. The Boivin et al. mechanism [15] had much shorter IDTs than the other mechanisms when the initial temperature was below $1200 \mathrm{~K}$. The Davis et al. mechanism [12] led to IDTs shorter in lower temperatures but longer in high temperatures when compared to others. This detailed $\mathrm{H}_{2} / \mathrm{CO}$ mechanism can lead to autoignition at $1020 \mathrm{~K}$ but requires a long IDT which is hundreds times of that of the reduced mechanism.

The different behaviours of the five mechanisms in the LES-LEM calculations can be related to their IDTs. It can be found that the shorter IDT is usually accompanied with higher conditional mean temperature. It is consistent with a previous study on methane flames [7]. The characteristics of IDT for three-dimensional flames are markedly different from the simple homogenous case when the two figures are examined. Only the reduced mechanism presents similar variations. Both modified from GRI3.0 [16], the Davis et al. [12] kinetics exhibits improved IDTs compared to Hong et al. [13], as shown in Figs. 9-10. 


\section{Conclusions}

A comparative study of five combustion kinetic mechanisms using the LES-LEM approach validated against a well-known nonpremixed hydrogen flame has been carried out. The five mechanisms including four detailed schemes (GRI3.0 [16], Davis et al. [12], Hong et al. [13], Ó Conaire et al. [14]) and one reduced scheme (Boivin et al. [15]) have been applied to the flame modelling of nonpremixed hydrogen combustion. This work highlights the necessity of accurate description of the chemical kinetics in LES of reacting flows. The performance of different chemical mechanisms is examined through comparison of the calculations with the experimental data, including instantaneous and means profiles, RMS fluctuations and ignition delay tests. The principal conclusions are as follows:

(1) All the five mechanisms yield comparable agreements with experimental data for temperature and the main species $\left(\mathrm{H}_{2}, \mathrm{H}_{2} \mathrm{O}, \mathrm{O}_{2}\right)$.

(2) The reduced kinetics over predicts the temperature peaks by $200-300 \mathrm{~K}$. And it displays significant inaccuracies in radical $\mathrm{HO}_{2}$ predictions. The steady-state assumption of radicals $\mathrm{O}$, $\mathrm{OH}, \mathrm{H}_{2} \mathrm{O}_{2}$ by the reduced mechanism has a strong impact on $\mathrm{HO}_{2}$, showing a much lower mass fraction and reaction rate.

(3) The models with different combustion kinetics differ significantly in producing key intermediate species $\left(\mathrm{HO}_{2}, \mathrm{H}, \mathrm{OH}\right)$ which represent different chemical pathways as the flame progresses downstream. The analyses on source term flux and scalar mass fraction plots indicate that accurate prediction of the intermediate species is important for the study of turbulence-chemistry interactions.

(4) The IDTs from simple homogeneous tests cannot be used to evaluate the IDTs for modelling practical flames, especially with detailed chemistry. To an extent there is a consistent pattern among the IDTs and the turbulent flame calculations for the different mechanisms, such as in the prediction of mean temperature profiles.

For the relatively simple test condition, all kinetic models show reasonable agreements especially for the mean quantities including species concentrations. Based on investigation of 
the intermediate species, it is observed that the mechanism by Ó Conaire et al. [14] could possibly give the best results among the five kinetic mechanisms. However, the reduced kinetics by Boivin et al. [15] results in a significant speed-up at nearly $75 \%$ in the three-dimensional case compared to the detailed ones, which is computationally advantageous.

\section{Acknowledgement}

This research was supported by the Fundamental Research Funds for the Central Universities (No. WK2320000034).

\section{References}

[1] Midilli A, Dincer I. Hydrogen as a renewable and sustainable solution in reducing global fossil fuel consumption. International Journal of Hydrogen Energy 2008;33:4209-22.

[2] Zheng J, Liu X, Xu P, Liu P, Zhao Y, Yang J. Development of high pressure gaseous hydrogen storage technologies. International Journal of Hydrogen Energy 2012;37:1048-57.

[3] Choudhuri AR, Gollahalli SR. Combustion characteristics of hydrogen-hydrocarbon hybrid fuels. International Journal of Hydrogen Energy 2000;25:451-62.

[4] Mira Martinez D, Jiang X, Moulinec C, Emerson DR. Numerical assessment of subgrid scale models for scalar transport in large-eddy simulations of hydrogen-enriched fuels. International Journal of Hydrogen Energy 2014;39:7173-89.

[5] Barlow RS, Fiechtner GJ, Carter CD, Chen JY. Experiments on the scalar structure of turbulent $\mathrm{CO} / \mathrm{H}_{2} / \mathrm{N}_{2}$ jet flames. Combustion and Flame 2000;120:549-69.

[6] Cabra R, Myhrvold T, Chen JY, Dibble RW, Karpetis AN, Barlow RS. Simultaneous laser Raman-Rayleigh-LIF measurements and numerical modeling results of a lifted turbulent 
$\mathrm{H}_{2} / \mathrm{N}_{2}$ jet flame in a vitiated coflow. Proceedings of the Combustion Institute 2002;29:1881-8.

[7] Cao RR, Pope SB. The influence of chemical mechanisms on PDF calculations of nonpremixed piloted jet flames. Combustion and Flame 2005;143:450-70.

[8] Echekki T, Gupta KG. Hydrogen autoignition in a turbulent jet with preheated co-flow air. International Journal of Hydrogen Energy 2009;34:8352-77.

[9] Hilbert R, Tap F, El-Rabii H, Thévenin D. Impact of detailed chemistry and transport models on turbulent combustion simulations. Progress in Energy and Combustion Science 2004;30:61-117.

[10] Mir Najafizadeh SM, Sadeghi MT, Sotudeh-Gharebagh R. Analysis of autoignition of a turbulent lifted $\mathrm{H}_{2} / \mathrm{N}_{2}$ jet flame issuing into a vitiated coflow. International Journal of Hydrogen Energy 2013;38:2510-22.

[11] Meier W, Prucker S, Cao MH, Stricker W. Characterization of turbulent hydrogen-air jet diffusion flames by single-pulse spontaneous Raman scattering. Combustion Science and Technology 1996;118:293-312.

[12] Davis SG, Joshi AV, Wang H, Egolfopoulos F. An optimized kinetic model of $\mathrm{H}_{2} / \mathrm{CO}$ combustion. Proceedings of the Combustion Institute 2005;30:1283-92.

[13] Hong Z, Davidson DF, Hanson RK. An improved $\mathrm{H}_{2} / \mathrm{O}_{2}$ mechanism based on recent shock tube/laser absorption measurements. Combustion and Flame 2011;158:633-44.

[14] Ó Conaire M, Curran HJ, Simmie JM, Pitz WJ, Westbrook CK. A comprehensive modelling study of hydrogen oxidation. International Journal of Chemical Kinetics 2004;36:603-22.

[15] Boivin P, Jiménez C, Sánchez AL, Williams FA. An explicit reduced mechanism for $\mathrm{H}_{2}$-air combustion. Proceedings of the Combustion Institute 2011;33:517-23.

[16] Smith GP, Golden DM, Frenklach M, Moriarty NW, Eiteneer B, Goldenberg M, et al. GRI-Mech 3.0, available at http://www.me.berkeley.edu/gri_mech/. 
[17] Mueller MA, Kim TJ, Yetter RA, Dryer FL. Flow reactor studies and kinetic modelling of the $\mathrm{H}_{2} / \mathrm{O}_{2}$ reaction. International Journal of Chemical Kinetics 1999;31:113-25.

[18] Saxena P, Williams FA. Testing a small detailed chemical-kinetic mechanism for the combustion of hydrogen and carbon monoxide. Combustion and Flame 2006;145:316-23.

[19] Ranga Dinesh KKJ, Jiang X, van Oijen JA. Numerical simulation of hydrogen impinging jet flame using flamelet generated manifold reduction. International Journal of Hydrogen Energy 2012;37:4502-15.

[20] Ranga Dinesh KKJ, Jiang X, van Oijen JA, Bastiaans RJM, de Goey, LPH. Hydrogen-enriched nonpremixed jet flames: Effects of preferential diffusion. International Journal of Hydrogen Energy 2013;38:4848-63.

[21] Yoo CS, Sankaran R, Chen JH. Three-dimensional direct numerical simulation of a turbulent lifted hydrogen jet flame in heated coflow: flame stabilization and structure. Journal of Fluid Mechanics 2009;640:453-81.

[22] Duwig C, Fuchs L. Large eddy simulation of a $\mathrm{H}_{2} / \mathrm{N}_{2}$ lifted flame in a vitiated co-flow. Combustion Science and Technology 2008;180:453-80.

[23] Ranga Dinesh KKJ, Jiang X, Kirkpatrick MP, Malalasekera W. Combustion characteristics of $\mathrm{H}_{2} / \mathrm{N}_{2}$ and $\mathrm{H}_{2} / \mathrm{CO}$ syngas nonpremixed flames. International Journal of Hydrogen Energy 2012;37:16186-200.

[24] Stanković I, Mastorakos E, Merci B. LES-CMC simulations of different auto-ignition regimes of hydrogen in a hot turbulent air co-flow. Flow, Turbulence and Combustion 2013;90:583-604.

[25] Katta VR, Aggarwal SK, Roquemore WM. Evaluation of chemical-kinetics models for n-heptane combustion using a multidimensional CFD code. Fuel 2012;93:339-50.

[26] Wang L, Liu Z, Chen S, Zheng C. Comparison of different global combustion mechanisms under hot and diluted oxidation conditions. Combustion Science and Technology 2012;184:259-76. 
[27] Pitsch H. Large-eddy simulation of turbulent combustion. Annual Review of Fluid Mechanics 2006;38:453-82.

[28] Ihme M, Pitsch H. Prediction of extinction and reignition in nonpremixed turbulent flames using a flamelet/progress variable model: 2. Application in LES of Sandia flames D and E. Combustion and Flame 2008;155:90-107.

[29] Ivana S, Bart M. LES-CMS simulations of a turbulent lifted hydrogen flame in vitiated co-flow. Thermal Science 2013;17:763-72.

[30] McMurthy PA, Menon S, Kerstein AR. A linear eddy sub-grid model for turbulent reacting flows: Application to hydrogen-air combustion. Symposium (International) on Combustion 1992;24:271-8.

[31] Kerstein AR. Linear-eddy modelling of turbulent transport. Part 6: Microstructure of diffusive scalar mixing fields. Journal of Fluid Mechanics 1991;231:361-94.

[32] Kerstein AR. Linear-eddy modelling of turbulent transport. Part 7: Finite-rate chemistry and multi-stream mixing. Journal of Fluid Mechanics 1992;240:289-313.

[33] Ströhle J, Myhrvold T. An evaluation of detailed reaction mechanisms for hydrogen combustion under gas turbine conditions. International Journal of Hydrogen Energy $2007 ; 32: 125-35$.

[34] Varga T, Nagy T, Olm C, Zsély IG, Pálvölgyi R, Valkó É, et al. Optimization of a hydrogen combustion mechanism using both direct and indirect measurements. Proceedings of the Combustion Institute 2015;35:589-96.

[35] Mira Martinez D, Jiang X. Large-eddy simulations of unsteady hydrogen annular flames. Computers \& Fluids 2013;80:429-40.

[36] Smith T, Menon S. Model simulations of freely propagating turbulent premixed flames. Symposium (International) on Combustion 1996;26:299-306.

[37] Torres DJ, Trujillo MF. KIVA-4: An unstructured ALE code for compressible gas flow with sprays. Journal of Computational Physics 2006;219:943-75. 
[38] Brown PN, Byrne GD, Hindmarsh AC. VODE: A variable-coefficient ODE solver. SIAM Journal on Scientific and Statistical Computing 1989;10:1038-51.

[39] Kee RJ, Rupley FM, Miller JA. Chemkin-II: A Fortran chemical kinetics package for the analysis of gas-phase chemical kinetics. Sandia National Laboratory., Livermore, CA (USA); 1989.

[40] Snyder A, Skinner G, Robertson J, Zanders DL. Shock tube studies of fuel-air ignition characteristics. Technical report AFAPL-TR-65-93, Air Force Aero-Propulsion Laboratory, Wright-Patterson, 1965.

[41] Slack M. Rate coefficient for $\mathrm{H}+\mathrm{O}_{2}+\mathrm{M}=\mathrm{HO}_{2}+\mathrm{M}$ evaluated from shock tube measurements of induction times. Combustion and Flame 1977;28:241-9.

[42] Craig RR. A shock tube study of the ignition delay of hydrogen-air mixtures near the second explosion limit. Technical report AFAPL-TR-66-74, Air Force Aero-Propulsion Laboratory, Wright-Patterson, 1966.

[43] Lutz A, Kee R, Miller J. SENKIN: A Fortran program for predicting homogeneous gas phase chemical kinetics with sensitivity analysis, Technical report SAND87-8248, Sandia National Laboratory, Livermore, CA, 1997. 


\section{Tables}

Table $1 \mathrm{H}_{2} / \mathrm{O}_{2}$ reaction mechanism

\begin{tabular}{|c|c|c|}
\hline & No. & Reaction \\
\hline \multirow{4}{*}{$\begin{array}{l}\text { Hydrogen-oxygen } \\
\text { chain reactions }\end{array}$} & $\mathrm{R} 1$ & $\mathrm{H}+\mathrm{O}_{2}=\mathrm{OH}+\mathrm{O}$ \\
\hline & $\mathrm{R} 2$ & $\mathrm{H}_{2}+\mathrm{O}=\mathrm{OH}+\mathrm{H}$ \\
\hline & R3 & $\mathrm{H}_{2}+\mathrm{OH}=\mathrm{H}_{2} \mathrm{O}+\mathrm{H}$ \\
\hline & $\mathrm{R} 4$ & $\mathrm{H}_{2} \mathrm{O}+\mathrm{O}=2 \mathrm{OH}$ \\
\hline \multirow{4}{*}{$\begin{array}{l}\text { Hydrogen-oxygen } \\
\text { direct recombination }\end{array}$} & R5 & $\mathrm{H}+\mathrm{H}+\mathrm{M}=\mathrm{H}_{2}+\mathrm{M}$ \\
\hline & R6 & $\mathrm{H}+\mathrm{OH}+\mathrm{M}=\mathrm{H}_{2} \mathrm{O}+\mathrm{M}$ \\
\hline & R7 & $\mathrm{O}+\mathrm{O}+\mathrm{M}=\mathrm{O}_{2}+\mathrm{M}$ \\
\hline & $\mathrm{R} 8$ & $\mathrm{H}+\mathrm{O}+\mathrm{M}=\mathrm{OH}+\mathrm{M}$ \\
\hline \multirow{6}{*}{$\begin{array}{l}\text { Hydroperoxyl formation } \\
\text { and consumption }\end{array}$} & R9 & $\mathrm{H}+\mathrm{O}_{2}+\mathrm{M}=\mathrm{HO}_{2}+\mathrm{M}$ \\
\hline & R10 & $\mathrm{HO}_{2}+\mathrm{H}=\mathrm{OH}+\mathrm{OH}$ \\
\hline & R11 & $\mathrm{HO}_{2}+\mathrm{H}=\mathrm{H}_{2}+\mathrm{O}_{2}$ \\
\hline & R12 & $\mathrm{HO}_{2}+\mathrm{H}=\mathrm{H}_{2} \mathrm{O}+\mathrm{O}$ \\
\hline & $\mathrm{R} 13$ & $\mathrm{HO}_{2}+\mathrm{O}=\mathrm{OH}+\mathrm{O}_{2}$ \\
\hline & $\mathrm{R} 14$ & $\mathrm{HO}_{2}+\mathrm{OH}=\mathrm{H}_{2} \mathrm{O}+\mathrm{O}_{2}$ \\
\hline \multirow{6}{*}{$\begin{array}{l}\text { Hydrogen peroxide } \\
\text { reactions }\end{array}$} & $\mathrm{R} 15$ & $\mathrm{OH}+\mathrm{OH}+\mathrm{M}=\mathrm{H}_{2} \mathrm{O}_{2}+\mathrm{M}$ \\
\hline & R16 & $\mathrm{HO}_{2}+\mathrm{HO}_{2}=\mathrm{H}_{2} \mathrm{O}_{2}+\mathrm{O}_{2}$ \\
\hline & $\mathrm{R} 17$ & $\mathrm{H}_{2} \mathrm{O}_{2}+\mathrm{H}=\mathrm{HO}_{2}+\mathrm{H}_{2}$ \\
\hline & $\mathrm{R} 18$ & $\mathrm{H}_{2} \mathrm{O}_{2}+\mathrm{H}=\mathrm{H}_{2} \mathrm{O}+\mathrm{OH}$ \\
\hline & R19 & $\mathrm{H}_{2} \mathrm{O}_{2}+\mathrm{OH}=\mathrm{H}_{2} \mathrm{O}+\mathrm{HO}_{2}$ \\
\hline & R20 & $\mathrm{H}_{2} \mathrm{O}_{2}+\mathrm{O}=\mathrm{HO}_{2}+\mathrm{OH}$ \\
\hline
\end{tabular}


Table 2 Chemical mechanisms used in the LES-LEM calculations

\begin{tabular}{|l|l|l|l|l|}
\hline Mechanism & No. species & No. steps & With Ar/He & Ref. \\
\hline GRI3.0* & 10 & 28 & $\mathrm{Ar}$ & {$[16]$} \\
\hline Davis et al. & 16 & 38 & $\mathrm{Ar} / \mathrm{He}$ & {$[12]$} \\
\hline Hong et al. & 10 & 20 & $\mathrm{Ar}$ & {$[13]$} \\
\hline Ó Conaire et al. & 10 & 21 & $\mathrm{Ar}$ & {$[14]$} \\
\hline Boivin et al. & 8 & 3 or 12 & None & {$[15]$} \\
\hline
\end{tabular}

*the carbon contained part was removed to accelerate the calculation 


\section{Figures}

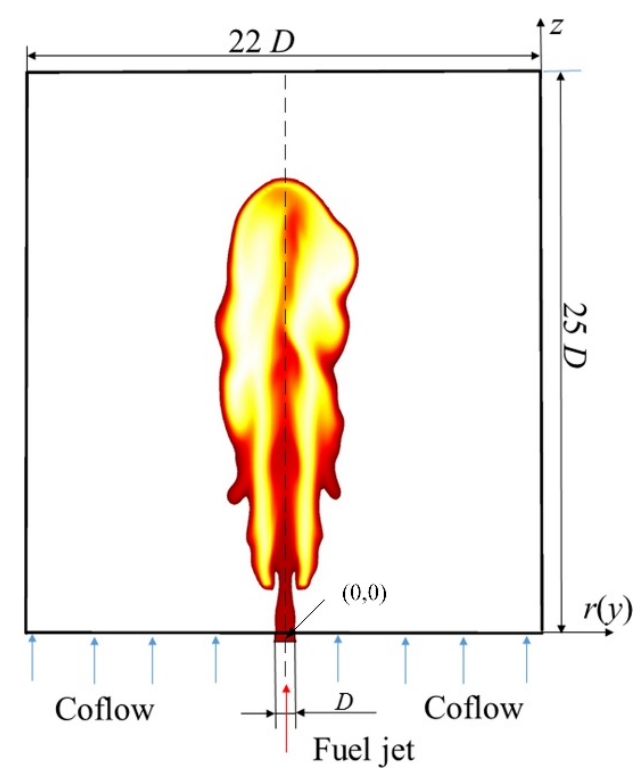

Fig.1 Schematic of the computational domain.
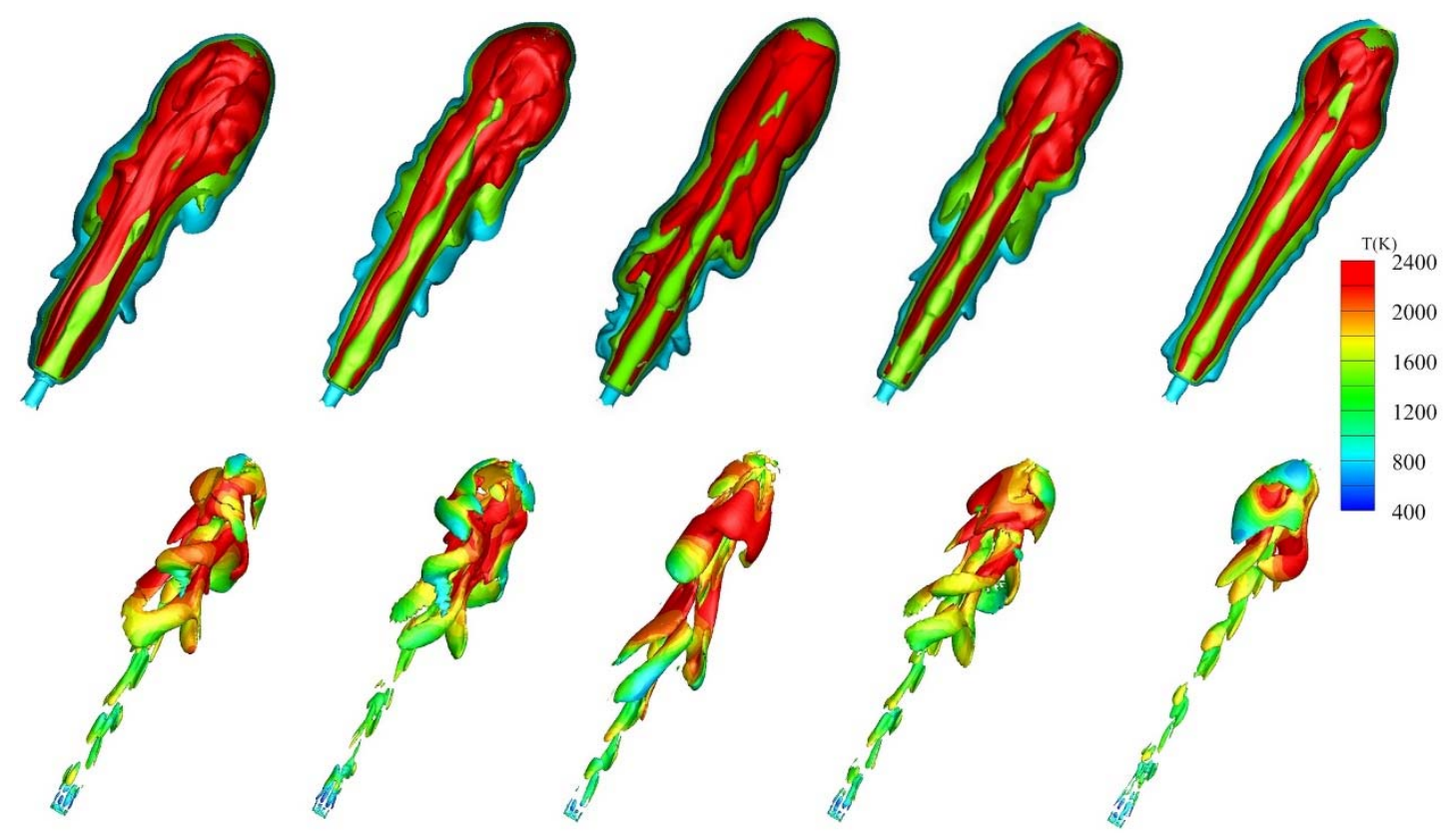

Fig. 2 Top: instantaneous three-dimensional iso-surfaces with iso-values of $800 \mathrm{~K}$ (blue), $1500 \mathrm{~K}$ (green) and 2200K (red); Bottom: instantaneous three-dimensional iso-surfaces of vorticity magnitude $\left(\omega_{1}=500 \mathrm{1} / \mathrm{s}\right)$ flooded by temperature. All plots are for the time instant of $0.024 \mathrm{~s}$ and correspond to the mechanisms of GRI3.0 [16], Davis et al. [12], Hong et al. [13], Ó Conaire et al. [14], and Boivin et al. [15] from the left to right. 

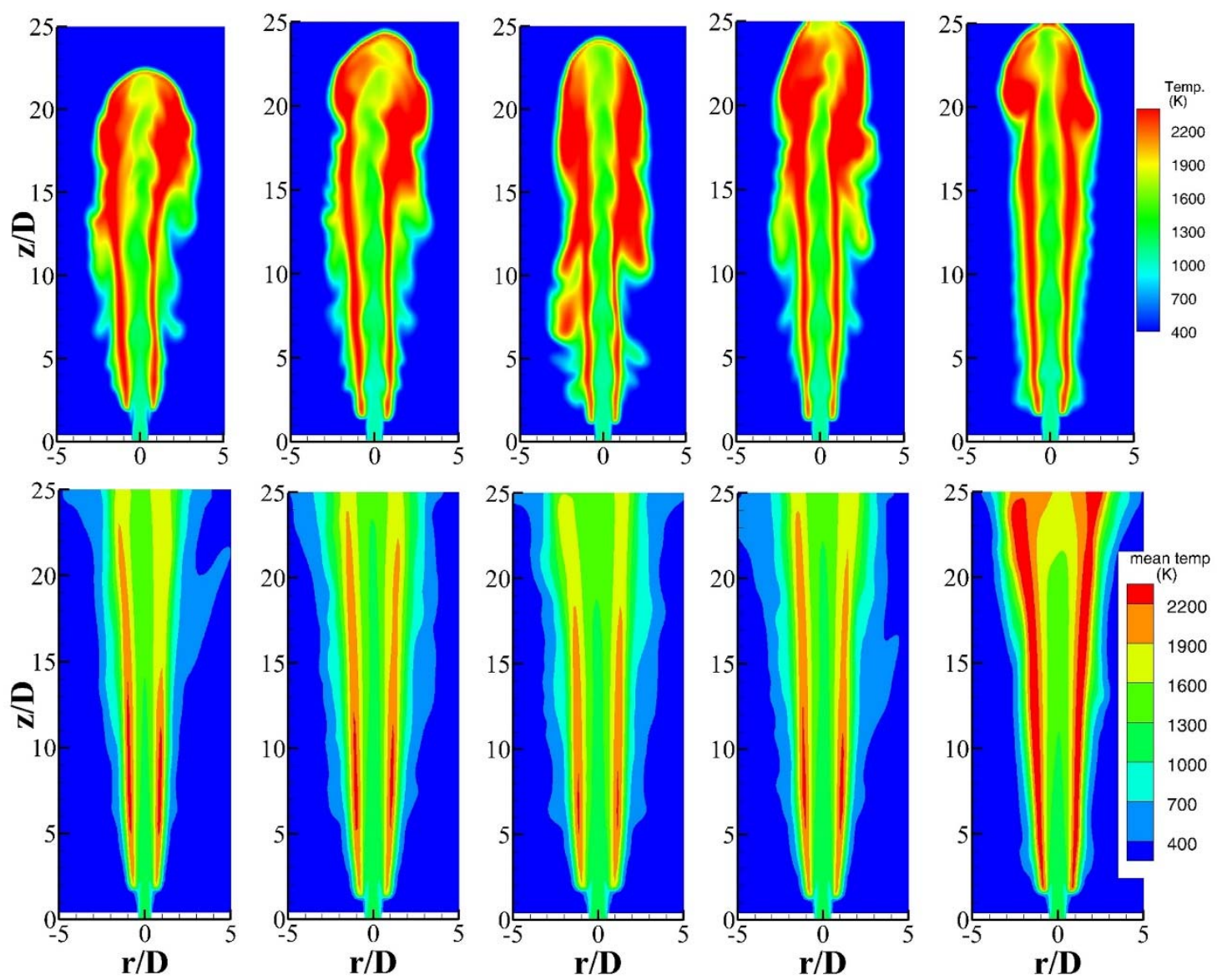

Fig. 3 Top: instantaneous cross-sectional temperature profile at time $=24 \mathrm{~ms}$; Bottom: mean temperature in the plane of $x(r)=0$. From the left to right: GRI3.0 [16], Davis et al. [12], Hong et al. [13], Ó Conaire et al. [14], and Boivin et al. [15]. 

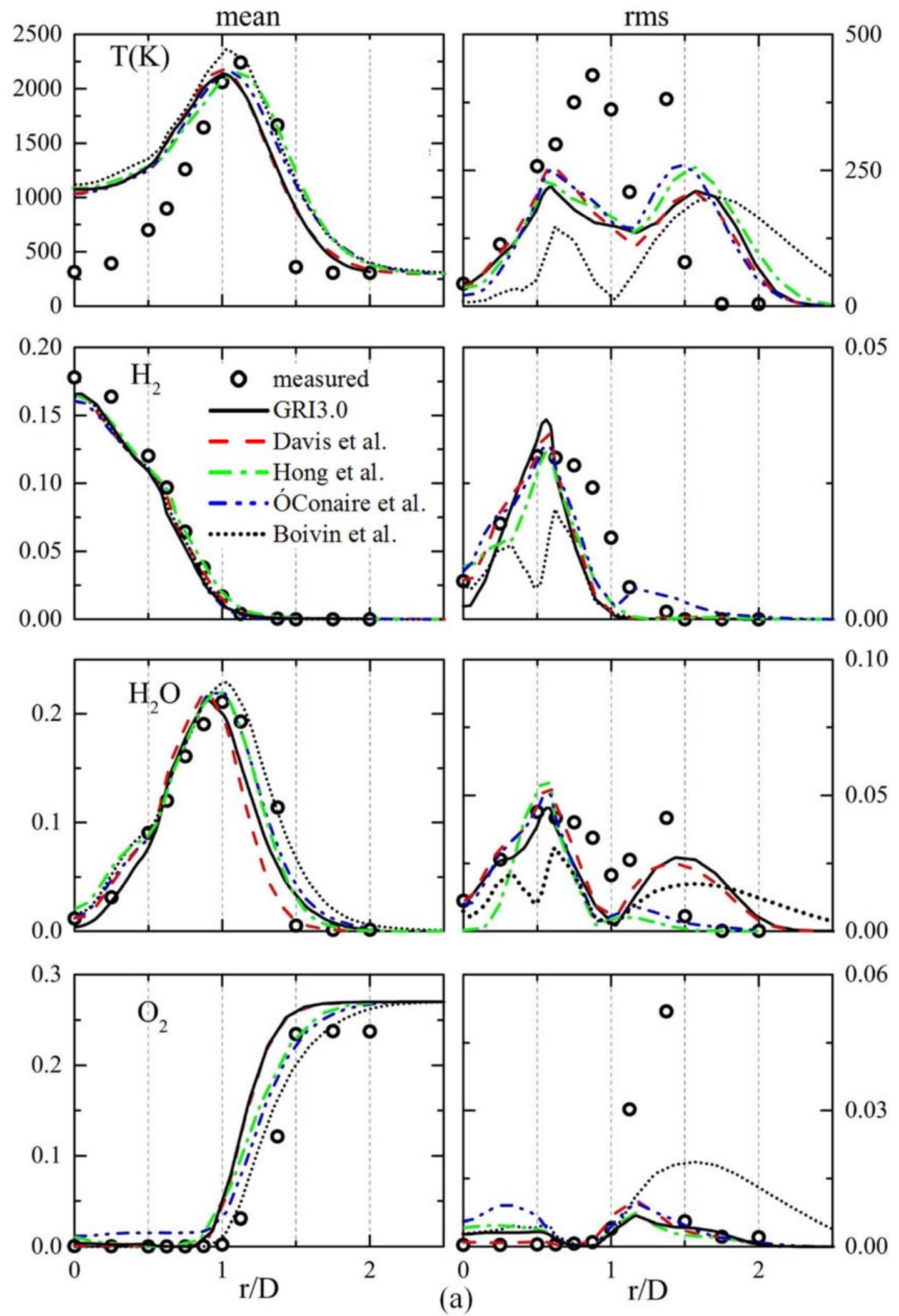

(a) 

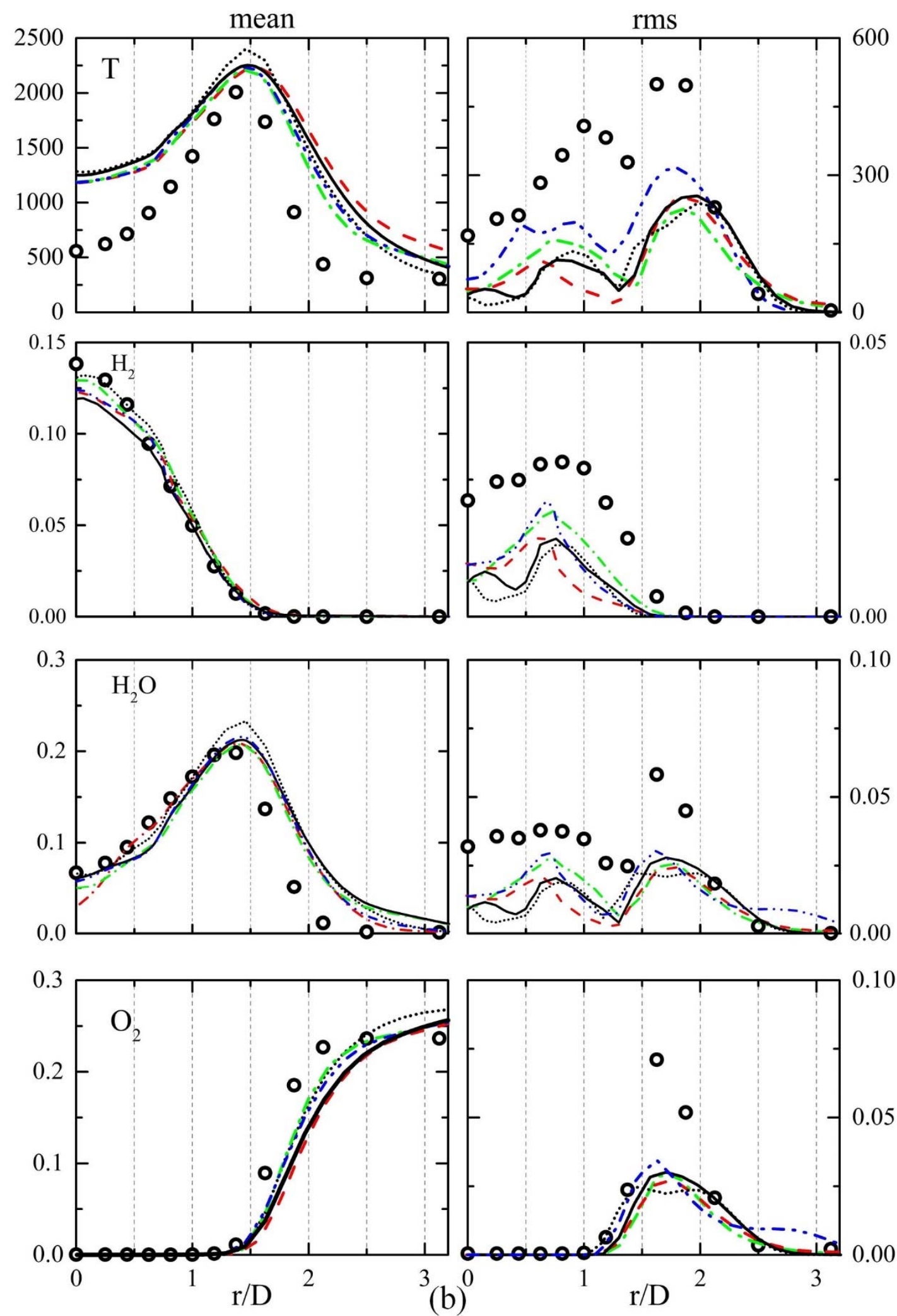

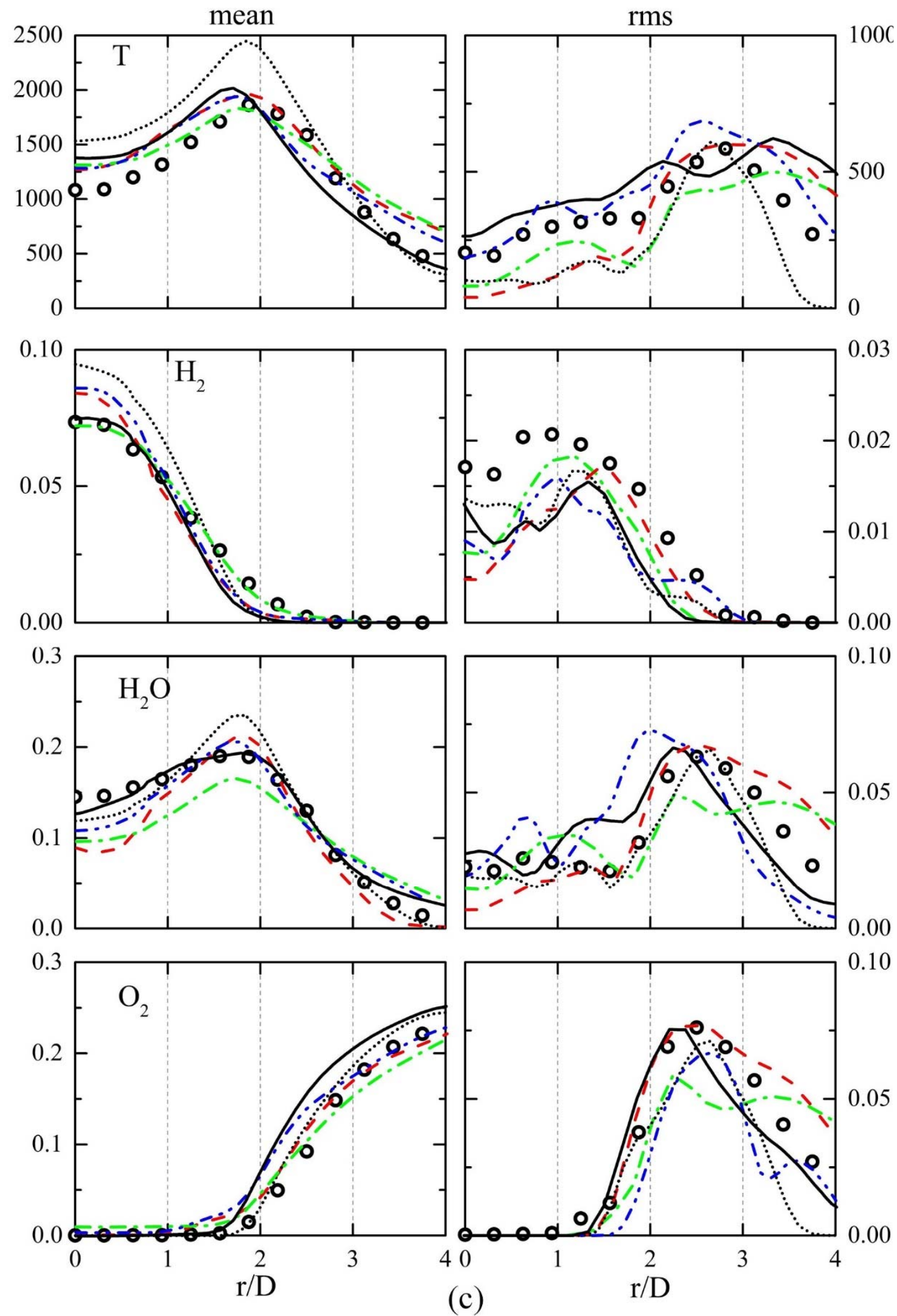

Fig. 4 Mean and RMS profiles for the temperature and mass fractions of selected species $\left(\mathrm{H}_{2}\right.$, $\mathrm{H}_{2} \mathrm{O}, \mathrm{O}_{2}$ ) at (a) $z / D=5$, (b) $z / D=10$ and (c) $z / D=20$ obtained from the five mechanisms (curves) in comparison with experimental data (circles). 

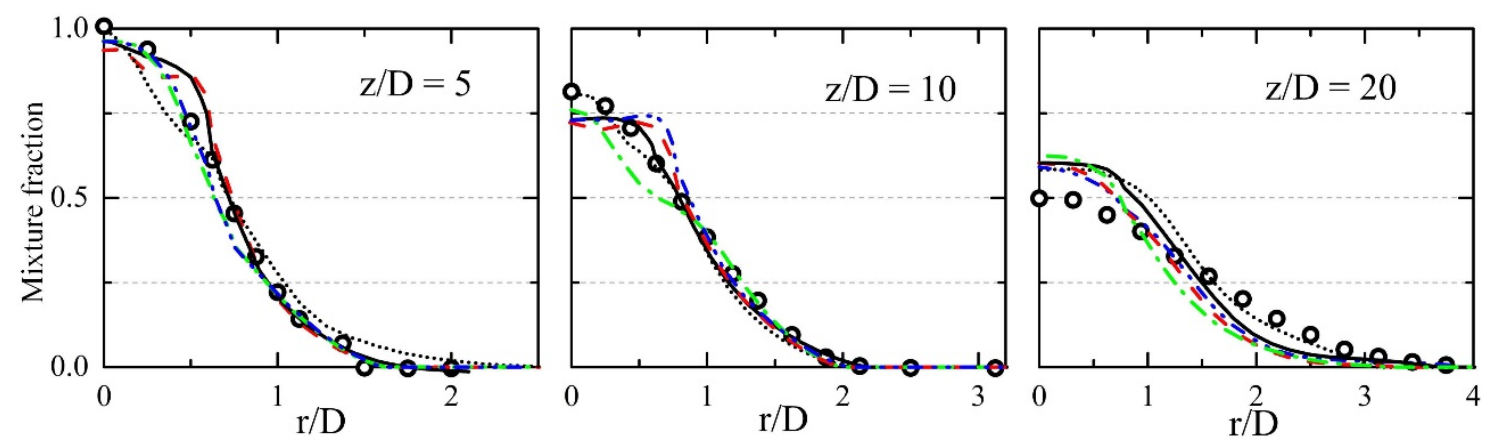

Fig. 5 The predicted mixture fraction profiles in the planes of $z / D=5,10,20$ compared with experimental data, symbol/line legends are the same as in Fig. 4. 

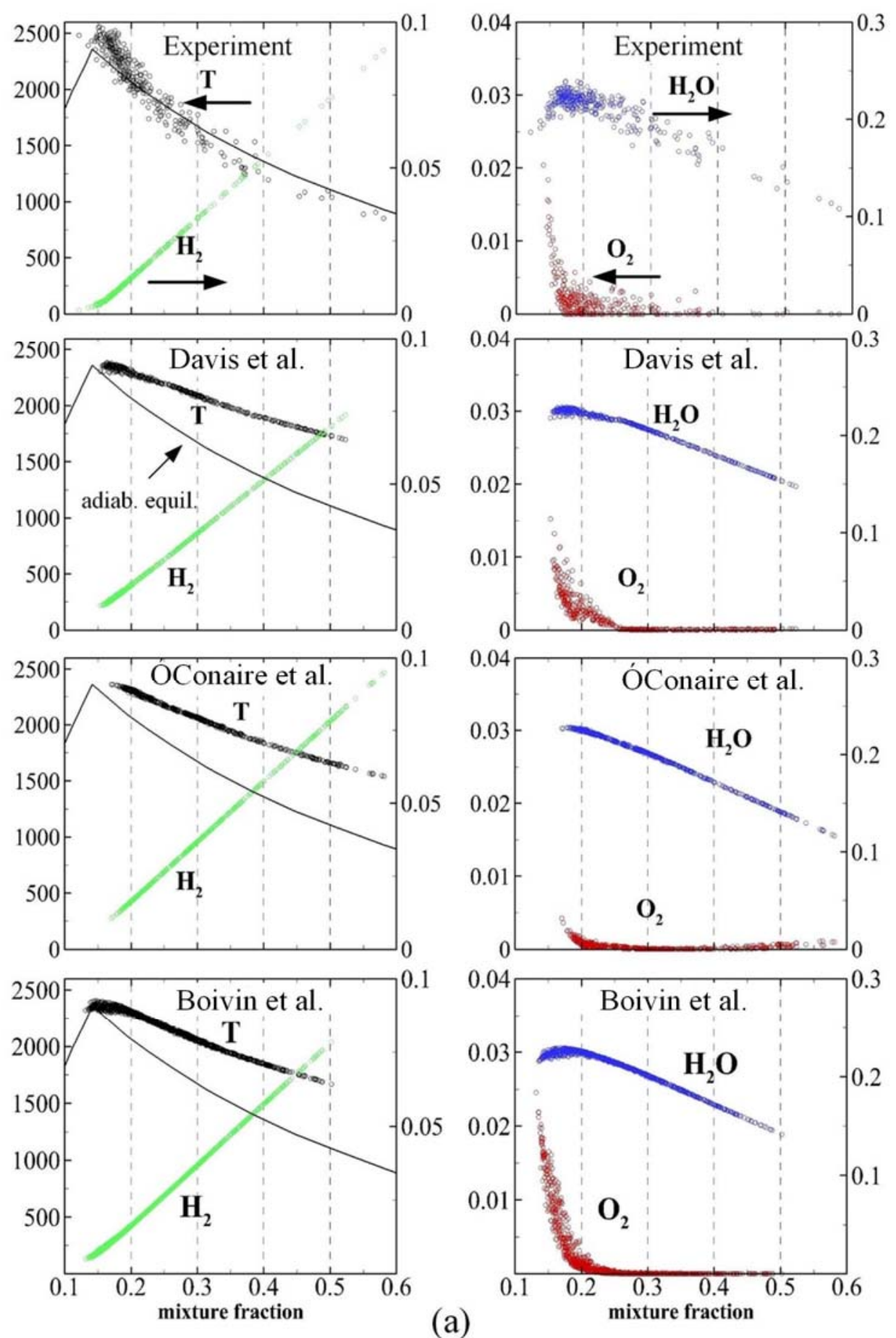

(a) 

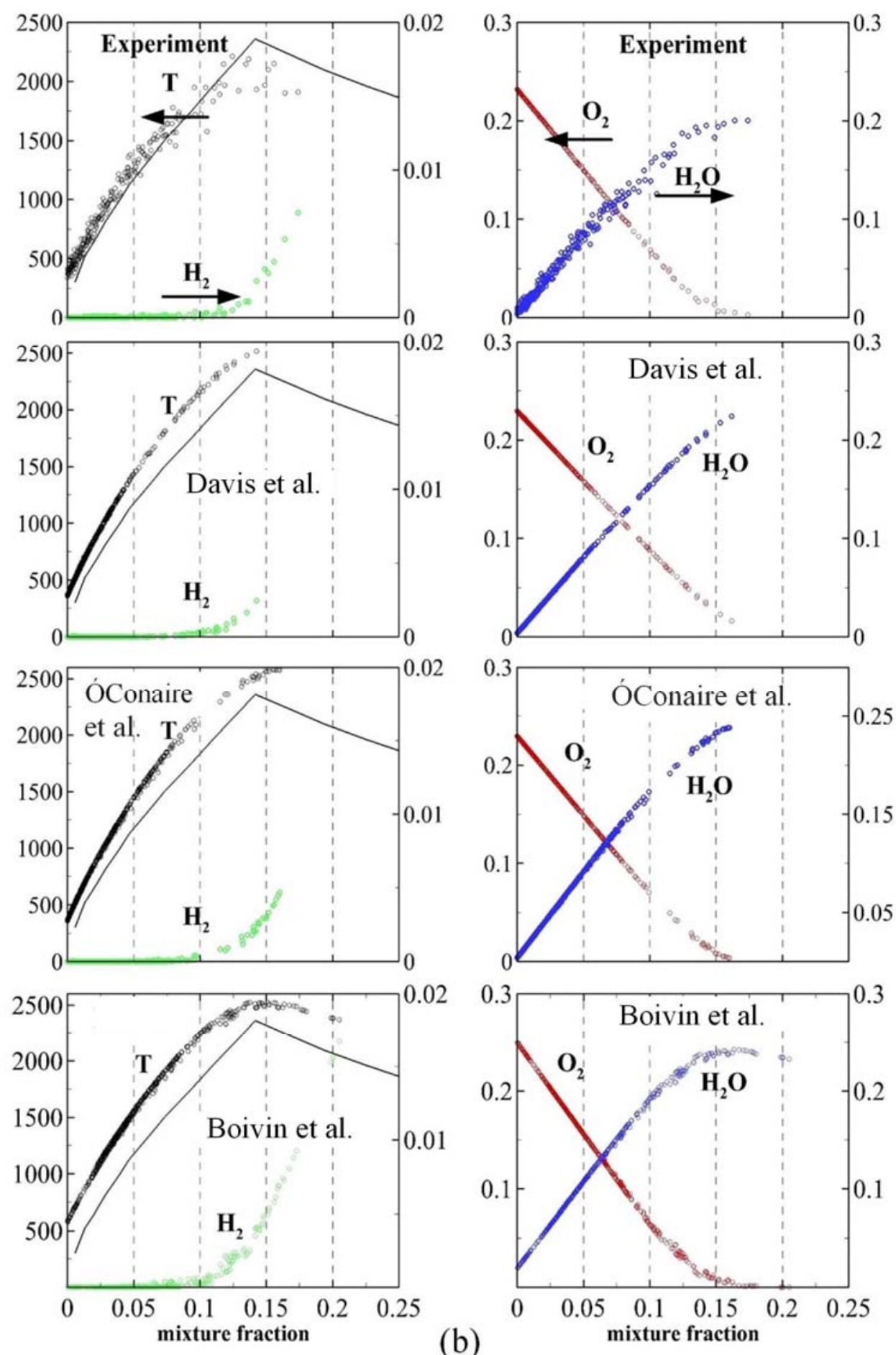

Fig. 6 Scalar plots of temperature and mass fractions of selected species $\left(\mathrm{H}_{2}, \mathrm{O}_{2}, \mathrm{H}_{2} \mathrm{O}\right)$ at the points of (a) $\mathrm{z} / \mathrm{D}=5.0, \mathrm{r} / \mathrm{D}=1.0$, (b) $z / D=20.0, r / D=3.125$ versus mixture fraction as obtained with Davis et al. [12], Ó Conaire et al. [14], and Boivin et al.[15] mechanisms in comparison with experiments. The solid black line represents the equilibrium adiabatic temperature. 

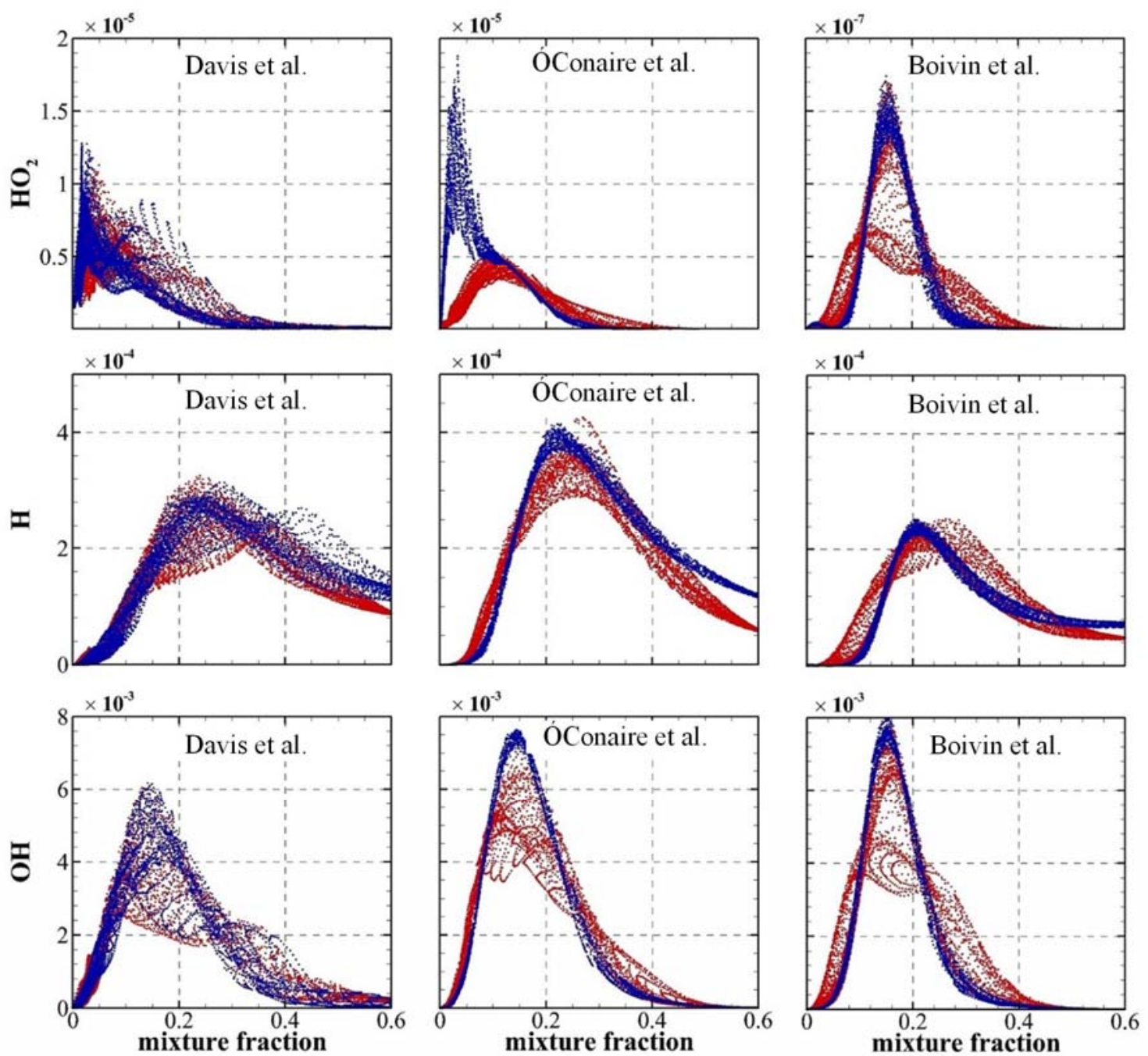

Fig. 7 Scalar plots of species $\mathrm{HO}_{2}, \mathrm{H}$ and $\mathrm{OH}$ versus mixture fraction in the planes $z / D=5$ (blue) and $z / D=20$ (red), samples with $\mathrm{T}<500 \mathrm{~K}$ are omitted for simplicity.
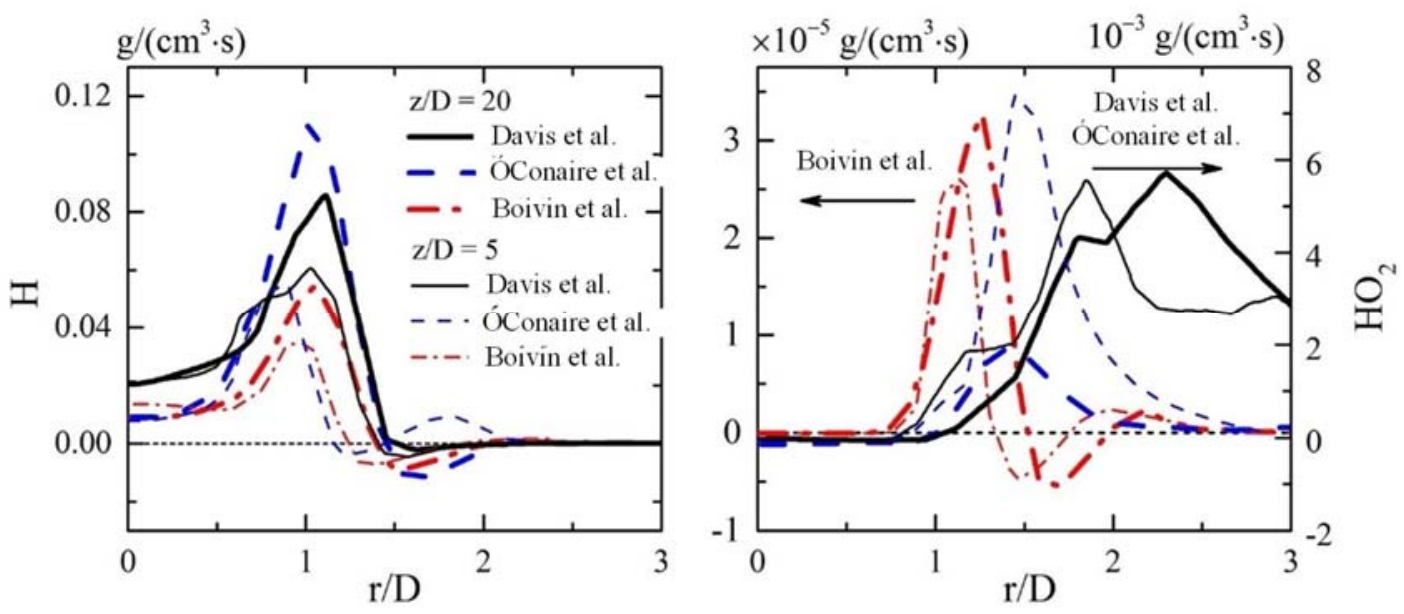

Fig. 8 Contributions of reaction in species conservation equations for radicals $H$ (left) and $\mathrm{HO}_{2}$ (right), in the planes of $z / D=5$ (fine lines), and $z / D=20$ (thick lines), respectively. 


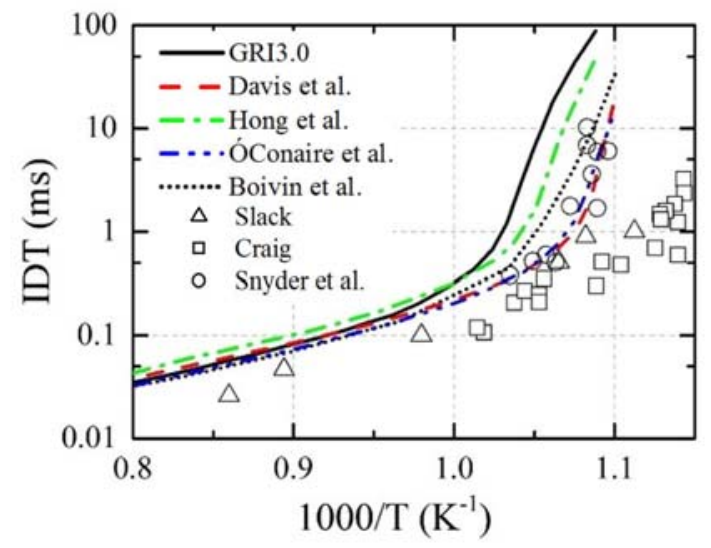

Fig. 9 Ignition delay time predicted by the five mechanisms for stoichiometric $\mathrm{H}_{2} /$ air mixtures compared with shock tube data.

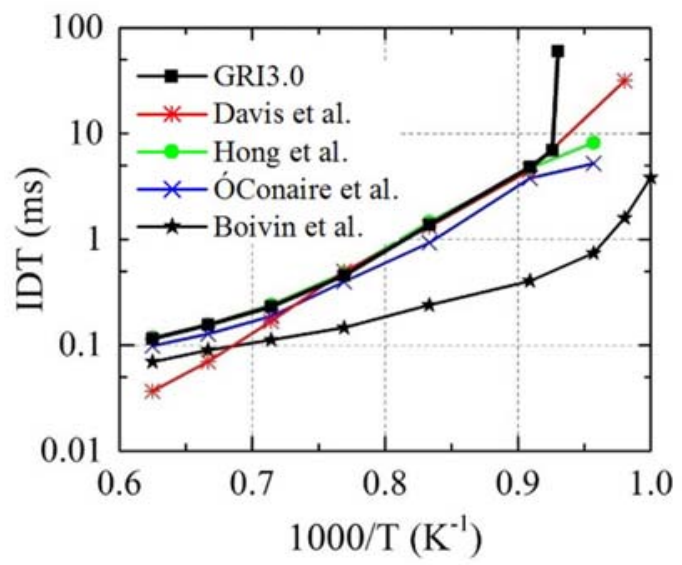

Fig. 10 Ignition delay time calculated with the five mechanisms for flame M2. 